\title{
Rational Choice and Policy Implementation: Implications for Interorganizational Network Management
}

\author{
Laurence J. O'Toole, Jr. \\ The University of Georgia
}

\begin{abstract}
Research on interorganizational policy implementation continues to be characterized by diverse theoretical approaches. It is perhaps surprising to observe, however, that formal and especially rational-choice approaches have been essentially neglected in the study of policy implementation processes. This article focuses on this matter and reaches mixed conclusions. An examination of how rational-choice approaches such as game theory might contribute to the enhancement of interorganizational management shows that serious limitations constrain what may be possible theoretically through the formal rational-choice representation and analysis of many interorganizational implementation settings. Nevertheless, and somewhat paradoxically, exploring these qualifications suggests a set of practical implications for the actual conduct of management in policy network settings.
\end{abstract}

Policy implementation, a subject of considerable scholarly interest for the past two decades, refers to the connection between the expression of governmental intention and actual results. Although implementation is sometimes accomplished through the efforts of a single administrative agency, increasingly success may require multiple organizational units. The importance of intergovernmental grant programs and regulatory mechanisms, the prominence of public-private partnerships, and the emergence of crosscutting policy problems on issues like health care, homelessness, and economic growth-these all testify to the centrality of interorganizational arrangements for dealing with today's implementation challenges.

This article focuses on understanding and managing implementation in the numerous cases in which parts of two or more organizations, sometimes even complex networks of interdependent actors, are required to cooperate and perhaps coordinate for policy success. Interunit implementation may face special challenges from the lack of authoritative and efficient channels for joint decision and actions, the complications of multilateral bargaining, and the diverse interests often represented. As a consequence, successful implementation can be especially daunting.

Other versions of this paper were presented at the Workshop on "Management in Interorganisational Networks" of the European Consortium for Political Research, Limerick, Ireland, March 30-April 4, 1992 and the National Conference on Public Management Research, Madison, WI, September 30 - October 2, 1993. 
Here I address the question of how one category of theory development might provide assistance for implementation in network settings. The argument examines formal, especially rational choice approaches such as game theory, to consider how such perspectives might contribute to an understanding of management in interorganizational networks for policy implementation. The first conclusion is that serious limitations constrain what may be possible through the formal rational-choice representation and analysis of many such settings. The second important conclusion, however, is that these limitations for theorists do not mean that practical implementation success itself must be problematic. In fact, an exploration of the limitations of formal approaches reveals the ways that practicing managers may succeed under challenging network conditions: the modelling problems themselves point systematically to the practical management possibilities. ${ }^{1}$

\section{Rational Choice and Interorganizational Implementation ${ }^{2}$}

There has been little agreement on a theory of interorganizational implementation (for documentation and analysis, see O'Toole, 1986; Goggin, Bowman, Lester, \& O'Toole, 1990; and Palumbo \& Calista, 1990). We need further efforts at theory building, both to advance the scholarly study of the subject and to encourage better practice. Research conducted thus far has been heavily inductive (Mazmanian \& Sabatier, 1989). To the extent that deductive approaches have been offered, these typically have either focused on single organizations (see Bendor, 1990; Noll \& Weingast, 1991) or have been characterized by a top-down, compliance orientation (for instance, Chubb, 1985). Both types are vulnerable to the criticisms advanced against top-down implementation theory.

Network theory and formal exchange models have received scant attention from scholars of interorganizational implementation, who have tended to utilize the notions of network and exchange in loose ways (for an exception, see Stoker, 1991; cf., Scharpf, 1993). Examining the potential applicability of rational-choice approaches helps us address two general questions. First, does such a perspective hold potential for advancing theory about interunit implementation? The answer summarized in this article is that such approaches face serious difficulties. Second, even if rational-choice analysis is limited in its direct theory-building applicability, can it serve a purpose by alerting analysts to matters of practical moment for those interested in network management? This more circumscribed but pragmatic objective receives attention in this article, which draws a cautiously optimistic conclusion. For understanding why rational-choice theoretical approaches face substantial impediments in turn points to the ways in which managers can enhance chances for practical implementation success. 


\section{Interorganizational Implementation: An Analysis ${ }^{3}$}

Interorganizational implementation, the action of two or more units on behalf of a public policy, can be conceptualized as a problem of cooperation and possibly coordination. ${ }^{4}$ Two broad reasons why interunit action is often more difficult are: (a.) the use of coordination mechanisms within single organizations can themselves render interorganizational coordination more problematic, and (b.) the forms of inducement to interunit cooperation are typically also weaker than those available within simpler structures.

Intraorganizational coordinating mechanisms-routines, for instance-work to simplify the search for optimum equilibria among individuals within organizational units. In so doing, however, these complicate searches for solutions across structures. Interorganizational implementation must typically be induced, yet inducements are often constrained by characteristics of the standard interunit network setting. Absent substantial quantities of either authority or common interest across the parties, and given the complications of collective action problems even where there are significant shared interests (see Hardin, 1968; Ostrom, 1990), exchange may have the most potential. Yet successful exchange is by no means assured. The complexity of multiunit settings can pose substantial impediments. Two of these complications are particularly important for assessing the potential of formal theory: the presence of substantial uncertainty and also, relatedly, the absence of sufficient institutionalization in the network setting. Both features pose challenges for modelling efforts. The following two subsections emphasize these limitations. The section that follows then explores implications for management.

\section{Uncertainty}

As implementers seek to give practical meaning to policy, they can be challenged by uncertainty arising from the setting in which they try to act. High levels of uncertainty in turn create complications for modelling. A consideration of implementation in network settings suggests that the number of sources of uncertainty in such cases, especially at the early stages of implementation, creates inherent limitations restricting the ability of formal approaches to model the most important elements of empirical cases.

Numerous aspects of uncertainty have been intensively analyzed in the literature on game theory. Here it is appropriate to summarize some of the complications for modelling. As the argument later in this article indicates, these complications carry ramifications for practice.

First, uncertainty is often present for participants in interunit settings because of lack of knowledge of other actors' true preferences. Second, the sheer number of units involved in the interorganizational effort, when coupled with the number of strategies potentially available to each, may be sufficiently large as to provide another source of uncertainty. The network in many actual cases may be too large for fully specified modelling.

Third, the complexity among the units may mean that the actors themselves, and not merely the analysts, face substantial uncertainties regarding the structure of interdependence itself. If the actors are linked reciprocally, the 
complexity of network structure may thus magnify the uncertainties stemming from the other sources already outlined.

A fourth point, much more well-known, is that problems of monitoring and enforcement can be substantial. "Second-order" collective action difficulties may reduce or eliminate monitoring or sanctioning altogether: all participants may have an interest in monitoring compliance among several organizations on an innovative social services program, for instance, but each may find the task too burdensome to handle alone and thus all may suffer from inadequate oversight. Once again, issues for modelling (and also for action) present themselves.

Another source of uncertainty has to do with the connectedness of strategic interactions in the network. First, the good news: The theory of connected or nested games offers suggestive ways of modelling important aspects of interorganizational implementation as well as other types of network settings (see, for instance, Alt \& Eichengreen, 1987; Alt, Putnam, \& Shepsle, 1988; Tsebelis, 1990). Furthermore, analysts have indicated how actors may buffer against the uncertainties stemming from such connectedness by segmenting their "games" and playing them separately (see Scharpf, 1990).

Now, however, the bad news (bad, that is, from the standpoint of those who hope to model such interunit settings): Another source of uncertainty here is second-order strategic behavior regarding the nature of the links themselves that bind the actors into their interdependence. Even as some seek segmentation of the games and therefore simplification of the layering, others may be advantaged by continuing to tie the games together. Complications for implementation practice can ensue when, for instance, a business firm insists on linking tax abatement decisions and city budget allocations to its "game" of negotiating with a local public agency on the terms of a public-private partnership. The essential point here, however, is that the tendency of networked actors to engage in such strategic linking makes the task of formalizing interunit bargaining exceedingly daunting. There may be virtually no end to the "moves" available in interorganizational negotiations, and models simply cannot capture the full array of options.

Uncertainty, in short, poses challenges from a number of directions to the potentially powerful idea of rational-choice analyses of implementation networks. It can sometimes also vitiate implementation practice, but this issue is treated separately later.

\section{Implementation Networks and Institutional Dynamics}

A great deal of attention has been devoted in recent years to the "new institutionalism" in the social sciences. Rational-choice approaches themselves have often been crafted to model the impact of basic institutional features in politically important settings such as elections, legislatures, and bureaucracies. The notion of institution as used in this discussion is meant to include not merely formal or officially adopted structures but all understandings regarding regularized action in social settings; Ostrom's idea of institutions as sets or clusters of working rules is apropos (see Ostrom, 1986a, 1986b, 1990). 
The issue of institutions is central in the current analysis because formal modelling (especially rational choice modelling, even through complex approaches such as connected games) must assume considerable institutionalization in the relevant setting, and yet many networks for implementation are not highly institutionalized-especially in the important early stages of implementation. A lack of institutionalization at the outset of multiunit implementation means that formal models inherently cannot capture the key elements of the social setting and develop robust predictions. Ex post facto explanation is the most that can be expected.

Some rational-choice approaches have addressed the question of how to model, or at least explore systematically, issues of institutional change (see Tsebelis, 1990). However, even under the most optimistic conditions these must assume a base institution from which to examine possible departures. When implementation develops across institutions, among units or groups that do not have at least the outlines of an interunit-institutional starting point, rationalchoice explanations become much less useful.

The point here goes to the question of theory development rather than the matter of management. The critique of rational-choice approaches sketched here implies inherent and serious limitations on what formal approaches can offer: models cannot provide much information regarding what is likely to happen in a given interorganizational implementation setting. ${ }^{5}$ But we cannot conclude from this discussion that cooperation itself (implementation success) is unlikely. Indeed, such a point would be a manifest absurdity. The literature of interorganizational implementation has now documented large numbers of "successful" implementation cases. Rather, the claim is that rational-choice approaches are not particularly helpful in the careful predictive modelling of such emergent processes.

So implementation in networks can be successful, even if it often cannot be formally modelled. How? Here is where the preceding analysis carries a more optimistic implication. Modelling and practical efforts are distinct, but they are linked by the important point that uncertainty and a lack of institutionalization pose potential threats to the success of each. The limitations for modelers, however, point in turn to the sites of most potent leverage for implementation managers. The review of impediments to modelling presented above-principally deriving from uncertainty and lack of institutionalization in the implementation setting-points directly to the most important opportunities for management intervention. Understanding the limitations on modelling efforts highlights simultaneously the important targets and methods of implementation management in practice: implementation managers in network settings can be successful by intervening at several points implied above to reduce uncertainty and institutionalize cooperation.

\section{Implications for Managing Implementation in Networks}

Interorganizational management has been of increasing interest in the field of public administration (see, for instance, O'Toole, 1988, 1989; Gage \& Mandell, 1990; Agranoff, 1991; Hanf, 1992; Hanf \& O'Toole, 1992; Milward, Provan, \& 
Else, 1993). The foregoing analysis can be used to identify and analyze the multiple possibilities for management in practice. The rest of this article explores modes of altering multiactor network settings to encourage cooperative solutions to implementation problems.

\section{Game Theory and the Implementation "Game"}

This article has shown that formal rational-actor analytic approaches cannot be expected to provide a theoretic resolution of interorganizational cases. Such perspectives require more clarity and resolution of uncertainty that can be expected in the early stages of most real cases. Nevertheless, the terms of reference of game-theoretic approaches, and the specific complications that can be expected in empirical settings, provide a practically useful template to identify and distinguish the types of managerial moves available for improving the odds of success in actual implementation "games." The following discussion uses the organizing perspective of the game-in the sense of interdependent, strategic choice - to analyze the managerial options for enhancing implementation.

One channel for influencing the likelihood of implementation success in network contexts reaches beyond the realm of "management," narrowly construed. It is the very content of policy that can significantly influence cooperative efforts in an implementation context. (For coverage of how policy design can influence the likelihood of interorganizational cooperation, see O'Toole, 1983.) Policies set the implementation game in motion; they constitute the initial step in determining the ways in which uncertainty may be reduced and institutionalization facilitated in the interests of policy objectives.

Policies alone cannot design full-blown cooperative institutions, but they are consequential. To the extent that they mandate behavior unacceptable to the actors, of course, they are unlikely to accomplish much; however, they can fix certain features of the context and perhaps signal appropriate modes or points of coordination. Such can be the function of policies designating lead agencies or procedural matters like requirements for hearings, scheduling stipulations, or deadlines. In more complex cases, they can affect actors' ability to reach Pareto-efficient equilibria (see Stoker, 1991). They also influence payoffs in at least some of the games in an interunit matrix through budgets, mandates, and the like. Furthermore, they influence the relevant structures of interdependence, as discussed earlier. Nevertheless, there has been surprisingly little research on how the attributes of policy are likely to influence the possibilities for cooperative network solutions. Rational-choice approaches point clearly to policy characteristics as key variables and also provide clues to the ways in which policy might matter. Recent attention being devoted to policy design may signal an emerging interest in this subject.

One final point regarding the issue of policy may be mentioned. Implementers themselves, including managers in the network, are not typically the same actors who craft the official policy. Managers' potential modes of influence over it, or over its redesign, are likely to be indirect and more subtle. It is not, then, a simple matter of managers' putting such knowledge to use. They more typically need to persuade at least some others. Thus another wrinkle: 
The network for policy formulation or reformulation overlaps that for implementation. Managing successfully in one may require understanding how various moves made at the intersection of the networks affect each set of games. Applying a rational-choice perspective, at least in general terms, to questions of institutional design for policy making may help implementation managers in network settings. ${ }^{6}$

\section{Network Management Options: Playing, Linking, and Altering the Implementation Game}

Often the implementation game cannot be fixed or arranged from the start by the careful design of policy. And in any event, managers in implementation networks may have to seek additional points of leverage over complex implementation processes. The analysis in the first part of this article showed that formal analysis cannot "solve" implementation puzzles. However, the sources of complication for formal analysis-principally, uncertainty and underinstitutionalization - point directly to the points of leverage for managers. Those in implementation networks can affect the outcome of the implementation game by moving in a number of ways, and at a number of levels, to reduce uncertainty and institutionalize cooperative arrangements in the interests of policy success.

By pointing to the problems (for modelers) of uncertainty and lack of institutional predictability at the outset of implementation, one thus identifies (for practice) the strategic sites for management intervention. Rational-choice analysis, therefore, suggests a conclusion broadly consistent with that reached in the more inductively generated implementation literature: the presence of an active and skillful multilateral broker (or network manager) at key points in the interunit structure can be crucial for the emergence and stability of cooperative solutions. Approaching such implementation settings from the standpoint of formal approaches, and with an appreciation for the range and importance of the barriers to interunit cooperation, can highlight the key role of managers in handling a wide variety of threats to cooperative action. Some of these are explored briefly here, in order of increasingly significant alterations to the implementation game.

Assisting the play of the game. Managers may be active, first of all, in the initiation of certain moves that do not alter the game-theoretic structure of the strategic situation-like signalling (for instance, letting units know of each others' involvement and interest, or pointing to possible points of cooperation), commitment, and iteration (predictable repetition of the interdependent action). When the coincidence of interests among implementation participants is relatively close, managers in networks may make all the difference by facilitating the strategic moves of the units involved, rather than by seeking to change the pattern of interdependence.

Linking games. Formal analysis points to the possibility that more forceful managerial moves may be necessary under more complex conditions of uncertainty or when games involve mixed, but not completely opposed, interests across participants. Here, success may be encouraged by managers propos- 
ing appropriate or potentially acceptable coordination points, that is, Paretoefficient equilibria. In the typically more complex interunit setting, such managerial actors can ease the equilibria identification and stabilization by proposing enforceable ways to link games among the actors (for instance, alternating equilibria to rotate the advantage across all parties). An illustration here would be suggesting that a donor unit accede to the needs or demands of a recipient agency in an intergovernmental grant program in exchange for the latter's deference to the former on a matter of mutual concern in a different program. In this fashion network managers may take the complexity and potential uncertainty often present in the network setting and utilize the potential connectedness of mixed-motive games to build stable agreements on a range of related issues. Even the formal examination of some of these games after the fact, including the identification of observed bargaining ranges, might be useful in explicating challenges and potential solutions to implementation management.

Another insight from rational-choice analysis refers to potential links between "levels" of games in the implementation context. Managers may be able to play key roles in mitigating the second-order collective action problem in implementation settings. Even if all necessary parties agree on the advisability of cooperation, such an agreement may require monitoring and enforcement to prevent unravelling. And yet although all parties may benefit from the agreement, in many cases no single party will have an interest in devoting the energy, time, and resources needed to monitor and enforce. However, a manager, either centrally designated or decentrally recognized, may be an ideal party. The self-interest of all parties may be served by contributing resources to the management function in the interests of dependable monitoring.

The first part of this article has shown that formal theory does not yield straightforward solutions to network implementation challenges, in part because of the ability of actors to link games strategically and in complex ways on behalf of their own interests. In considering implications for practice, however, this modelling limitation becomes a managerial opportunity: implementation managers, too, can act strategically by linking games of interdependent choice among the participants in an implementation effort, and they can do so with the aim of enhancing chances for practical success.

\section{Changing the game: Active implementation management}

Managers may increase the likelihood of implementation by facilitating the play of the strategic game when interests are closely aligned but coordination is needed. They may improve the odds of success in more complicated circumstances by explicitly connecting the implementation game to other parallel games or to a second-order monitoring or enforcement game. Sometimes, however, these options are either unavailable or insufficient. Circumstances requiring the greatest managerial creativity and effort, therefore, are likely to arise when the game is unplayable, that is, when the only solutions in a gametheoretic sense are choices that vitiate the policy's intent. We can identify a number of options for managers' altering the implementation game itself. Formal analyses of interdependent choice define games in terms of the preferences of participants and the structure of their interdependence. Similarly, then, 
managers can consider trying to change the implementation game to reduce uncertainty and institutionalize cooperative action by influencing preferences of those in the network or shifting the structure of interdependence. Each of these possibilities is thus identified with the aid of formal theory, although technically such moves lie outside the bounds of formal analysis (each involves changing the game rather than solving it). The following discussion, then, illustrates how rational-choice perspectives can assist in the analysis of active forms of implementation management, even if such approaches cannot usually produce formal, deductive "solutions" to problems of cooperation.

Influencing preferences. Managers may employ persuasion to increase perceived common interest as well as to catalyze agreement during negotiations. Formal theory operates by analyzing given preferences among interdependent actors (individuals or organizations), not by considering possibilities for shifts in these preferences. Yet practical implementation management may be assisted by encouraging changes that would increase the prospects for cooperative solutions.

Persuasion can work at several levels if actors are intendedly yet limitedly rational. Participants in a network may be influenced in their evaluations of specific expected consequences by their counterparts in other units and, certainly, by a network manager. Managers may find chances to alter perceived payoffs for the players-perhaps with the assent of all parties-and thus encourage cooperative outcomes. Further, because transaction costs may be considerable, managers in complex settings can facilitate cooperation by working to develop generally accepted understandings of "exchange rates" across resource types and perhaps building an institutional memory for some of the important if intangible debits and credits across units in the network (this task assists exchange and also monitoring).

Persuasion can influence choice at another level by convincing actors of the advantages of stable cooperation more generally among the units, even if the short-run or narrowly prudential calculation for the immediate task seems to argue against it. And persuasion can be important not only for actors' evaluations of alternatives and consequences but also for their basic interpretation of complicated signals from elsewhere (see, for instance, Kahneman \& Tversky, 1984).

Implementation managers can also use persuasion in a network to encourage the development of appropriate norms: norms of cooperation and others that enhance predictability in a setting of nascent institutionalization. Norms are important parts of the institutional setting, even if they are sometimes unnecessarily neglected in rational-choice formulations (see Elster, 1989, for a provocative exception). Furthermore, and in a fashion related to the reduction of second-order collective action problems discussed above, network managers can call attention to violations of such norms, either privately or across broader parts of the network setting, thus monitoring and enforcing patterns of cooperation.

By so doing, and by encouraging the development of norms of reciprocity, civility, and mutual respect, two important consequences may follow. First, these norms begin a process of network institutionalization that itself helps to reduce uncertainty and increase the ability and incentive of the various actors to seek 
cooperative solutions. And second, the development of such norms stimulates the beginnings of a climate of trust among the units, thus also reducing uncertainty and encouraging longer-term cooperation in a more subtle fashion. This conclusion follows from the impact of trust itself on the temporal perspectives of rational actors. Formal as well as experimental research has shown that trust in those with whom one has to make interdependent decisions means that the relevant actors are less likely to discount steeply their cooperative investments in the future (Axelrod, 1984; Stoker, 1991).

There are likely to be multiple opportunities for network managers to encourage the development of trust. Indeed, the mere presence of an individual or unit with recognized responsibilities for the interunit venture increases the likelihood of trust because other actors may begin to assume the presence of some monitoring and enforcement. Additional modes of developing trust are numerous. Indeed, in his analysis of the importance of trust over opportunism in many interunit settings, Sabel notes that 'the connection between situation and outcome as observable by an outsider is ... quite loose ... The outcome can only be explained by reference to the history of a (perhaps changing) bundle of local conditions, including of course the participants' changing views about the advantages and feasibility of cooperation" (1993, p. 20; see also Ostrom, 1990). These conditions are naturally subject to some influence by network managers (Sabel's "superintendents"). Two illustrations can indicate once again how the form of analysis used here is likely to point to possibilities. One is for network managers to be guided in directing information flows and timing within the network not only by the technical requisites of the policy but also by the need to respect confidences and avoid embarrassments of organizational units whose mutual trust may be essential for long-term success. A second implication of formal analysis is that managers may be advantaged by seeking to engage the various units initially in relatively low-risk cooperative ventures with each other. Success (that is, cooperation) at ostensibly unimportant interorganizational matters may breed success at larger enterprises.

Shifting the structure. Network managers can also take advantage of opportunities to alter the interunit structure itself to encourage cooperation. There can be many possibilities, and network managers themselves are best situated to evaluate their potential in a specific policy context. One fashion in which this issue has already been raised is the discussion of managers working strategically to separate or link potentially distinguishable games because the process of connecting two or more games itself constitutes a shift in the structure of interunit interdependence.

Another possibility, interestingly enough, works in the opposite direction: to reduce interdependence by employing buffering devices, rather than to link games for encouraging cooperation. Scholars using rational-choice approaches have analyzed ways of buffering networks, or portions of networks, from such sources of uncertainty as channels for backward induction. One type of buffering sometimes observable in interunit settings is the conscious reduction of requirements for joint decision making to those necessary for serving the interests of both (all) parties. This mode, called "negative coordination" by Mayntz and Scharpf (1975), was first described in German administrative settings and 
can simplify at least some of the complexity (see also Scharpf, 1978). Managers, in turn, can look for ways of decoupling portions of joint decision making if the task doesn't actually call for these. This point should not be taken to mean that some simplified public-choice logic is appropriate. Negative coordination may be unacceptable for many reasons.

An overall implication of this analysis of structural change for those interested in practical interunit management is that it is the overall structure, not simply the discrete and directly observable, often dyadic interactions, that is most significant in implementation. The overall structure heavily influences the answers to such central questions as who can make relatively autonomous moves, as well as who is strategically advantaged, in terms of payoff range and distribution in games where interests do not clearly mesh. The ability to analyze and compare network structures systematically has advanced considerably in recent years. Consequently, it may be important for those who seek improvement in managers' ability to call for interunit cooperation to encourage the use and further refinement of network analysis. Rational-choice approaches have shown deductively that ostensibly small adjustments in interunit structure can make for large alterations in outcomes. An analogous point is that it may be important for those concerned with managing implementation to encourage a more systematic examination of structural options.

One example is apropos. Despite the great political interest in privatization in numerous Western national contexts during the 1980s and 1990s, and despite the current ferment in Eastern Europe on this issue, the privatization phenomenon constitutes a host of quite different strategies, and these approaches in turn rely on different structural arrangements. How we can understand these and whether and how managers can encourage appropriate cooperative efforts in circumstances of complex public-private interdependence, are issues that analysts have hardly begun to explore. It is obvious, therefore, that more rigorous examination of a wider variety of structural arrangements is sensible for both practical and scholarly ends.

There are, of course, many additional fashions in which interorganizational managers might be able to influence structural change in the direction of cooperative arrangements. Indeed, the point made earlier regarding the lack of institutionalization in the nascent network setting may here be seen as an opportunity. Although rational-choice modelling is rendered problematic at a pre- or proto-institutional stage, still the lack of poorly designed structure (for the purpose at hand) can be counted as a practical advantage that skillful managers may exploit.

And even if it is not typically possible to design the interunit structure comprehensively, from the point of view of the network manager there may be multiple opportunities to alter the arrangement. To the extent that institutionalized arrangements do not favor cooperative solutions to problems of interdependence, managers may be able to take advantage of ad hoc situations to encourage a shift, even if only an incremental adjustment, when the episodic salience of an issue peaks. Examples might be establishing a lead agency, agreeing to stable funding for an interunit coordinating group, or decentralizing program decisions to organizations that have the most to gain from success. 
Indeed, even modest structural adjustments may considerably affect outcomes of multiunit games.

\section{Conclusion}

Rational-choice approaches may seem attractive for the analysis of issues of interorganizational implementation. Perspectives like game theory offer several advantages, including the rigor of deductive theory, the potential to unite strengths of both top-down and bottom-up perspectives by treating all relevant actors as strategic players, and an apparatus to assist in conceptualizing interdependence across "games" as well as across actors and decisions. Still, actual implementation networks contain complications that modelling can neither ignore nor fully address. The obstacles to rational-choice efforts are well-illustrated by the issues of uncertainty and institutionalization.

Nevertheless, considering interorganizational implementation from the perspective of rational choice is not futile. Less-formal analyses using the perspective of rational choice offer potential utility, especially in terms of management practice. Although it is not possible in most interesting cases to deduce rigorously modelled predictions regarding actual implementation settings, the concepts of rational choice provide leverage to scholars of network management as well as to managers themselves. The limitations of such approaches point to ways in which managers can increase the odds of cooperation in the direction of policy among diverse organizational units. Although the analysis here is far less than a practical manual for implementers, its coverage of the differentiated landscape of interorganizational implementation may provide some options to which implementers might turn.

Considering the implementation setting via approaches such as game theory focuses attention on issues of broad significance. Examples from this analysis include the central role of exchange and persuasion in implementation, the importance of uncertainty (and its diverse sources) as a potential barrier, and the numerous analytically coherent, even if empirically disparate, ways in which the interunit manager can influence interdependent action in the direction of cooperative outcomes. To improve management of networked implementation, more comprehensive exploration of these issues is essential.

\section{Notes}

'Managing interorganizational networks involves developing and maintaining cooperative links-and possibly achieving some generally appreciated objectives-in and through the interunit pattern (see Gage \& Mandell, 1990). The meaning is close to the "reticulist" function of Friend, Power, and Yewlett (1974), as well as the notions of "fixing" (Bardach, 1977) policy implementation or engaging in multilateral brokerage (Mandell, 1984) and policy entrepreneurship (for instance, Kingdon, 1984).

${ }^{2}$ This section and the one following contain brief summaries of recent analyses exploring the limitations and opportunities for rational choice contributions to 
the theoretical literature (for instance, O'Toole, 1993). The present article extends the analysis to the issue of interorganizational/network management. ${ }^{3}$ The argument in this section is based on and developed more fully in O'Toole (1993).

${ }^{4}$ In James Thompson's terms, reciprocal interdependence, but not the pooled or sequential varieties, demands conscious mutual coordination or strategic interaction (1967). Strategic varieties of rational-choice theory fit those cases in which coordination matters (see O'Toole, 1993; Scharpf, 1990).

${ }^{5}$ There may nevertheless be some value to a more limited application of the rational-choice approach by students of policy implementation. One option is to investigate when and how simplifying assumptions in network settings can legitimately be used to allow the application of game theory or similar approaches (see Scharpf, for instance, 1990, 1991). Complementary strategies (discussed more carefully in O'Toole, 1993) include the following:

- modelling cases of observed "success" in policy implementation;

- modelling cases in which success might have been expected but that produced disappointing results in practice;

- examining structurally "easy" settings, interunit implementation cases in which substantial institutionalization allows for a more readily interpretable modelling effort; and

- explicating discrete, identifiable, recurring, and potentially significant portions of a larger and more complicated interorganizational setting.

Further, to the extent that these research approaches yield insights into the world of interorganizational implementation, they may also generate implications for management.

${ }^{6}$ Ostrom's terminology may be helpful here: designing institutions for policy making - "constitutional" issues - may be addressable in part via rational-choice approaches and may in turn carry implications for implementation management.

\section{References}

Agranoff, R. (1991). Human services integration: Past and present challenges in public administration. Public Administration Review, 51(6), 1-11.

Alt, J. E., \& Eichengreen, B. (1987). Overlapping and simultaneous games: Theory and applications. Presented at the NBER Conference on The Political Economy of International Macroeconomic Policy Coordination. Andover, MA.

Alt, J. E., Putnam, R. D., \& Shepsle, K. A. (1988). The architecture of linkage. Presented at the Workshop on Connected Games: Theory, Methodology, and Applications. Max-Planck-Institut für Gesellschaftsforschung, Cologne. Axelrod, R. M. (1984). The evolution of cooperation. New York: Basic Books. Bardach, E. (1977). The implementation game. Cambridge: MIT Press.

Bendor, J. (1990). Formal models of bureaucracy: A review. In N. Lynn \& A. Wildavsky (Eds.), Public administration: The state of the discipline. Chatham, $\mathrm{NJ}$ : Chatham House.

Chubb, J. (1985). The political economy of federalism. American Political Sci- 
ence Review, 79, 994-1015.

Elster, J. (1989). The cement of society: A study of social order. New York: Cambridge University Press.

Friend, J. K., Power, J. M., \& Yewlett, C. J. L. (1974). Public planning: The inter-corporate dimension. London: Tavistock.

Gage, R. W., \& Mandell, M. P. (Eds.). (1990). Strategies for managing intergovernmental policies and networks. New York: Praeger.

Goggin, M. L., Bowman, A. O'M., Lester, J. P., \& O'Toole, L. J., Jr. (1990). Policy implementation: Toward a third generation. Glenview, IL: Scott Foresman/Little Brown.

Hanf, K. I. (1992). Networks as purposeful instruments of policy management. Presented at the Workshop on "Management of Interorganisational Networks," European Consortium for Political Research, Limerick, Ireland, March 30-April 4.

Hanf, K. I., \& O'Toole, L. J., Jr. (1992). Revisiting old friends: Networks, implementation structures, and the management of inter-organizational relations. European Journal of Political Research, 21, 163-180.

Hardin, G. (1968). The tragedy of the commons. Science, 162, 1243-1248.

Kahneman, D., \& Tversky, A. (1984). Choices, values, and Frames. American Psychologist, 39, 341-350.

Kingdon, J. W. (1984). Agendas, alternatives, and public policy. Boston: Little Brown.

Mandell, M. (1984). Application of network analysis to the implementation of a complex project. Human Relations, 37 (August), 659-679.

Mayntz, R., \& Scharpf, F. W. (1975). Policy making in German federal bureaucracy. Amsterdam: Elsevier.

Mazmanian, D. A., \& Sabatier, P. A. (1989). Implementation and public policy (rev. ed.). Latham, MD: University Press of America.

Milward, H. B., Provan, K. G., \& Else, B. A. (1993). What does the "hollow state" look like? In B. Bozeman (Ed.), Public management: The state of the art (pp. 309-322). San Francisco: Jossey-Bass.

Noll, R. \& Weingast, B. (1991). Rational actor theory, social norms, and policy implementation: Applications to administrative processes and bureaucratic culture. In K. R. Moore (Ed.), The economic approach to politics: A critical reassessment of the theory of rational action. New York: Harper Collins.

O'Toole, L. J., Jr. (1983). Interorganizational cooperation and the implementation of labour market training policies: Sweden and the Federal Republic of Germany. Organization Studies, 4, 129-150.

O'Toole, L. J., Jr. (1986). Policy recommendations for multi-actor implementation: An assessment of the field. Journal of Public Policy, 6, 181-210.

O'Toole, L. J., Jr. (1988). Strategies for intergovernmental management: Implementing programs in interorganizational networks. International Journal of Public Administration, 11, 417-441.

O'Toole, L. J., Jr. (1989). Goal multiplicity in the implementation setting: Subtle impacts and the case of wastewater treatment privatization. Policy Studies Journal, 18, 3-22.

O'Toole, L. J., Jr. (1993). Multiorganizational policy implementation: Some limitations and possibilities for rational choice contributions. In F. W. Scharpf 
(Ed.), Games in hierarchies and networks (pp. 1-39). London: Westview. Ostrom, E. (1986a). An agenda for the study of institutions. Public Choice, 48, 3-25.

Ostrom, E. (1986b). A method of institutional analysis. In F.-X. Kaufmann, G. Majone, \& V. Ostrom (Eds.), Guidance, control, and evaluation in the public sector. New York: Walter de Gruyter.

Ostrom, E. (1990). Governing the commons. Cambridge: Cambridge University Press.

Palumbo, D. J., \& Calista, D. J. (Eds.). (1990). Implementation and the policy process: Opening up the black box. New York: Greenwood Press.

Sabel, C. F. (1993). Constitutional ordering in historical context. In F. W. Scharpf (Ed.), Games in hierarchies and networks (pp. 65-123). London: Westview.

Scharpf, F. W. (1978). Interorganizational policy studies: Issues, concepts, and perspectives. In K. I. Hanf \& F. W. Scharpf (Eds.), Interorganizational policy making. London: Sage.

Scharpf, F. W. (1990). Games real actors could play: The problem of connectedness. Unpublished manuscript, Max-Planck-Institut für Gesellschaftsforschung, Cologne.

Scharpf, F. W. (1991). Crisis and choice in European social democracy. Ithaca, NY: Cornell University Press.

Scharpf, F. W. (Ed.). (1993). Games in hierarchies and networks. London: Westview.

Stoker, R. B. (1991). Reluctant partners: Implementing federal policy. Pittsburgh: University of Pittsburgh Press.

Thompson, J. D. (1967). Organizations in action. New York: McGraw-Hill.

Tsebelis, G. (1990). Nested games. Berkeley: University of California Press.

Laurence J. O'Toole, Jr. is professor of political science at the University of Georgia. His research interests include interorganizational policy implementation and management in complex networks. He has recently been investigating the applicability of formal approaches to these topics. 